\title{
EFEKTIVITAS PERAN PERKUMPULAN PETANI PEMAKAI AIR (P3A) BANDA TANGAH DAERAH IRIGASI (DI) BANDA PAMUJAAN DALAM PENGELOLAAN JARINGAN IRIGASI TERSIER DI KECAMATAN LUBUK SIKARAH, KOTA SOLOK
}

\author{
Yuri Gita Putri $^{1}$, Yuerlita ${ }^{2}$, Ferdhinal Asful ${ }^{3}$ \\ 1,2,3 Jurusan SosialEkonomi Pertanian, Fa kultas Pertanian, Universitas Andalas \\ *email koresponden: yuerlita @yahoo.com
}

\begin{abstract}
Abstrak
Penelitian ini bertujuan untuk mengetahui efektivitas danfaktor-faktor yang mempengaruhi peran P3 A B anda Tangah da la m mengelola jaringan iriga si tersier di Keca matan Lubuk Sikarah. Metode yang digunakan a dalah metode desk ript if kuantitatif, dengan data primer dan data sekunder. Teknik pengumpulan data dengan observasi, wa wanc ara mendalam dengan informan kunci, dan survei. Hasil penelitian ini menunjukkan bah wa efektivitas peran P3 A Banda Tangah da lam pengelolaan jaringan irigasi tersier dalam kategori tinggi ya knidengan skor 50,83. Hal inika rena P3 A B a nda Tangah menjalankan perannya dengan baik, mulai darioperasi jaringan iriga si, pemeliharaan jaringan iriga si, rehabilitasijaringan iriga si dan penanganan konflik. Faktor faktor efektivitas peran P3 A Banda Tangah yaitu kepemimpinan P3A dengan skor 14,43, waktu pertemuan P3A dengan skor 7,07, fungsitugas P3 Adengan skor 2,63, tingkat penguasaan materi oleh PPL dengan skor 8,43 dan tingkat karya PPL dengan skor 5,7. Berdasarkan analisis regresi linear berga nda, terdapat 3 faktor yang berpengaruh signifik an terhadap efektivitas peran P3A Banda Tangah yaitu kepemimpinan P3 A, waktu perte muan P3Adan tingkat penguasaan materi oleh penyuluh. Peneliti memberikan saran, untuk peran P3 Ad alam pe melihara an jaringan diharapkan P3A mampu menyediakan papan peringatan untuk tidakan pencegahan di sekitar jaringan iriga si agar petani mampu menjaga kebersihan jaringan iriga si da n untuk kegiatan kegiatan yang dia dakan oleh P3 A, pen gu rus dan petani anggota diharapkan mampu meningkatkan partisipasi/keikutsertaannya a gar efektivitas peran P3A dapat terca pai optimal.
\end{abstract}

Kata kunci: Agribisnis, petani, kopi

\begin{abstract}
This study aims to determine the effectiveness and to know thefactors that influence of the role of P3A Banda Tan gah in managing tertiary irrigation networks in Lubuk Sikarah Subdistrict. The method used in this research is quan titative descriptive method, used are primary data and secondary data. Data collection techniques were carried out by observation, in-depth interviews with key informants, and surveys. The results of this study indicate that the effectivene ss of the role of P3A Banda Tangah in the management of tertiary irrigation networks is in the high category with a score of 50.83. This is because P3A Banda Tangah performs its role well, starting from irrigation network operations, maintenance of irrigation networks, rehabilitation of irrigation networks and handling conflicts. The factors of effectiveness of the role of P3ABanda Tangah are P3A leadership with a score of 14.43, P3A meeting time with a score of 7.07, P3A task function with a score of 2.63, mastery level of material by PPL with a score of 8.43 and the level of PPL work with scores 5.7. Based on multiple linear regression analysis, there are 3 factors that significantly influence the effectiveness of the role of P3ABanda Tangahnamely P3A leadership, P3A meeting timeand level of ma stery of the material by the instructor. The researchers gave suggestions, for the role of P3A innetwork maintenance it is expected that P3A can provide a warning board for prevention measures around irrigation networks so that farmers a re able to maintain clean irrigation networks and for activities organized by $P 3 A$, members and managers are expected to increase participation/participation so that the effectiveness of the role of the P3Acan be achieved optimally.
\end{abstract}

Keywords: P3A Banda Tangah, tertiary irrigation, management, effectiveness 


\section{PENDAHULUAN}

Pengelolaan pengairan ditentukan oleh tiga unsur utama yang menjadi kunci keberhasilan dalam mencapai tujuan pengelolaan sumberdaya pengairan . Ketiga unsur tersebut adalah (1) tersedianya sumberdaya $(R)$ atau resource bagi pengelolaan irigasi secara memadai, sumberdaya tersebut diantaranya adalah sumberdaya fisik (bangunan saluran irigasi), sumberdaya manusia dan sumberdaya modal, (2) tersedianya organisasi $(O)$ atau organisation yang "fungsional" dalam memanfaatkan sumberdaya melalui suatu mekanisme pengaturan, serta (3) norma/aturan $(N)$ atau norms yang menjadi acuan efektif bagi organisasi untuk mengatur dan memanfaatkan sumberdaya pengairan secara adil dan efisien. Tidak memadainya R-O-N atau tidak sinergi dari ketiga unsur R-O-N dalam pengelolaan sumberdaa air (irigasi) akan menimbulkan permasalahan dalam pengelolaan pengairan (Saadah et al. , 2012)

Upaya mengevaluasi jalannya suatu organisasi dapat dilakukan melalui konsep efektifitas. Menurut Stokke dalam (Junita \& Buchori, 2016) efektivitas organisasi dicapai melalui tiga mekanisme, yaitu biaya yang akan saling mempengaruhi antar organisasi yang menimbulkan koordinasi, norma atau regulasi yang berlaku dalam organisasi, dan kebijakan yang mempengaruhi tujuan dari organisasi tersebut. Interaksi kelembagaan mengacu pada saling ketergantungannya kelembagaan pemerintah dalam pengaturan sehingga efektivas kelembagaan dipengaruhi oleh koordinasi antar kelembagaan tersebut (Nielsen dkk, 2013 dalam (Junita \& Buchori, 2016). Koordinasi berperan penting dalam merumuskan pembagian tugas, wewenang, dan tanggung jawab dalam organisasi, sekaligus melahirkan jaringan hubungan kerja yang diperlukan oleh organisasi (Faguet, 2004 dalam (Junita \& Buchori, 2016). Peran P3A terhadap irigasi adalah untuk melakukan pengelolaan secara menyeluruh terhadap irigasi agar fungsinya sebagai penyalur air ke lahan pertanian dapat terjamin.
P3A Banda Tangah dalam Operasi dan Pemeliharaannya (OP) menerapkan IPAIR (Iuran Pengelolaan Air). IPAIR adalah iuran yang dipungut dari petani pemakai air atas jasa dan pelayanan irigasi yang telah disediakan. Pada iuran ini(IPAIR) juga terdapat permasalahan yaitu seringnya anggota P3A tidak membayar iuran padahal jumlah yang ditetapkan sekali panen cukup terjagkau yakni senilai satu sukat padi atau setara \pm Rp. 10.000. Selain IPAIR, di P3A Banda Tangah juga memiliki kebijakan berupa AD/ART (Anggaran Dasar dan Anggaran Rumah Tangga) yang diperbarui setiap pergantian kepengurusan. Kepengurusan P3A Banda Tangah ini diganti sekali 5 tahun sekali.

Permasalahan jaringan irigasi tersier yang dihdapi petani secara keseluruhan adalah: 1) Jumlah debit air bertambah tanpa terkendali, 2) letak sawah relatif jauh dari saluran, tidak diperhitungkan dalam distribusi air dan anjuran teknologi yang berada di bagian hilir, 3) Penyadapan air secara liar dengan pompa berlanjut tanpa sangksi, 4) Pintu air banyak yang tidak berfungsi, dan 5) Produktifitas padi sangat beragam antara bagian hulu dan hilir, merupakan masalah mendasar yang diakibatkan dari buruknya pengelolaan jarinagan irigasi tersier. Pengelolaan jaringan irigasi tersier terdapat berbagai tahapan dan proses yang panjang untuk itu apabila disetiap prosesnya terjadi masalah maka akan mempengaruhi output dari pengelolaan itu sendiri. Kelembagaan yang memegang tanggung jawab dalam hal pengelolaan ini menjadi faktor penting berhasil tidaknya pengeloaan jaringan irigasi tersier. Namun ditingkat kelembagaan sendiri juga sering ditemukan permasalahan terkait dengan sumber daya manusia yang terlibat di dalamnya. Keaktifan seorang anggota menjadi kunci keberhasilan dari lembaga tersebut dalam menjalankan fungsinya. Peran lembaga menjadi fokus yang akan disorot untuk melihat efektif tidaknya lembaga tersebut dalam mengelola lembaganya. Pengelolaan jaringan irigasi dimulai dari daerah petak primer, sekunder sampai dengan tersier dan kuarter. Namun 
pengelolaan yang melibatkan petani secara penuh terdapat pada petk tersier.

\section{METODE PENELITIAN}

Metode penelitian yang digunakan dalam penelitian ini adalah metode survey dengan pendekatan kuantitif dan penjelasan deskriptif. Populasi pada penelitian ini adalah anggota P3A Banda Tangah yang terdiri dari 142 orang, dimana terbagi menjadi pemilik sawah (62 org) dan penggarap sawah (80 org), sedangkan sampel yang diambil sebanyak 30 orang.

\section{Interval}

Tabulasi data yang dilakukan adalah menganalisis tingkat efektivitas P3A Banda Tangah dan menganalisis faktor faktor yang mempengaruhi efektifitas P3A Banda Tangah di Kecamatan Lubuk Sikarah Kota Solok dengan menggunakan rumus interval. Analisis yang digunakan untuk melihat pengaruh faktor-faktor yang mempengaruhi efektivitas dengan evektivitas peran P3A itu sendiri adalah analisi regresi linear berganda. Penentuan skor dilakukan dengan memberikan skor pada taip jawaban yang diberikan oleh responden. Skor berkisar dari 3-1. Jawaban a diberi skor 3, jawaban b diberi skor 2, dan jawaban c diberi skor 1.Untuk membuat kriteria pengukuran efektivitas peran P3A Banda Tangah Daerah Irigasi (DI) Banda Pamujaan dalam pengelolaan irigasi tersier di kecamatan Lubuk Sikarah, Kota Solok, maka digunakan rumus (Ridwan, 2007).

Interval $=\frac{\text { Skor terting gi }- \text { Skor terendah }}{\text { Banyak Kelas }}$

\section{Analisi Regresi Linear Berganda}

Menurut (Ghozali, 2013) analisis regresi adalah analisis yang mengukur pengaruh variabel independen $(\mathrm{X})$ terhadap variabel dependen $(\mathrm{Y})$. Pengukuran pengaruh variabel yang melibatkan lebih dari satu variabel bebas (X1, X2, ,X3, X4, X5), digunakan analisis regresi linear berganda, disebut linear karena setiap etimasi atas nilai diharapkan mengalami peningkatan atau penurunan mengikuti garis lurus. Berikut estimasi regresi linear berganda. Pada penelitian ini variabel indepensen $(\mathrm{X})$ adalah kepemimpinan P3A, waktu pertemuan P3A, fungsi tugas P3A, penguasaan matei oleh penyuluh, dan tingkat karya penyuluh, sedangkan variabel dependen (Y) adalah efektivitas peran P3A Banda Tangah dalam pengelolaan jaringan irigasi tersier.

$Y=\alpha+\beta_{1} X_{1}+\beta_{2} X_{2}+\beta_{3} X_{3}+\beta_{4} X_{4}+\beta_{5} X_{5}+e$

Keterangan :

$\mathrm{Y}=$ variabel terikat

$X(1,2,3,4,5)=$ variabel bebas

$\alpha=$ nilai konstanta

$\beta(1,2,3,4,5)=$ nilai koefisien regresi

$\mathrm{E}=$ Std Error

\section{HASIL DAN PEMBAHASAN PENELITIAN}

\section{Efektivitas Peran P3A Banda Tangah Dalam Pengelolaan Jaringan Irigasi Tersier.}

Jaringan irigasi tingkat tersier yang dikelola oleh P3A dalam penelitian ini adalah P3A Banda Tangah Daerah Irigasi Banda Pamujaan, Kecamatan Lubuk Sikarah, Kota Solok. Penilaian efektivitas peran P3A Banda Tangah dalam pengelolaan jaringan irigasi tersier seperti yang terlihat pada Tabel 1. Untuk rekapitulasi data terkait efektivitas peran P3A Banda Tangah dalam pengelolaan irigasi tersier dapat dilihat pada lampiran 11 .

Dari data yang disajikan pada Tabel 1 dapat diketahui bahwa tingkat efektivitas peran P3A Banda Tangah dalam pengelolaan irigasi tersier dalam kategori tinggi, yaitu pada titik 48,767 yang terletak pada interval 44,34 - 57. Dari data tersebut dapat diketahui efektivitas peran P3A yang paling tinggi terdapat pada perannya dalam penanganan konflik yaitu dengan rata rata 2,786 dan peran P3A dalam operasi jaringan irigasi dengan rata rata sama yaitu 2,786, selanjutnya peran $\mathrm{P} 3 \mathrm{~A}$ dalam pemeliharaan jaringan irigasi dengan rata rata 2,413 dan peran P3A 
dalam rehabilitasi jaringan irigasi dengan rata rata 1,822 . rata rata 2,63 dan waktu pertemuan P3A dengan rata rata 2,357 .

Tabel 1. Tingkat Efektivitas Peran P3A Banda Tangah

\begin{tabular}{lllll}
\hline Atribut & Skor Total & Total Rata-Rata & Rata-Rata & Kategori \\
\hline Operasi Jaringan Irigasi & 545 & 19,50 & 2,79 & Tinggi \\
Pemeliharaan Jaringan & 497 & 19,30 & 2,41 & Tinggi \\
Rehabilitasi Jaringan Iriga si & 164 & 4,03 & 1,82 & Sedang \\
Penangan Konflik & 178 & 5,93 & 2,97 & Tinggi \\
\hline Total & & $\mathbf{4 8 , 7 6 7}$ & $\mathbf{4 8 , 7 7}$ & \\
\hline
\end{tabular}

Penilaian efektivitas peran P3A Banda Tangah, Daerah Irigasi Banda Pamujaan, Kecamatan Lubuk Sikarah dimulai dari kegiatan operasi jaringan irigasi, pemeliharaan jaringan irigasi, rehabilitasi jaringan irigasi dan penanganan konflik.

\section{Faktor Faktor yang Mempengaruhi Efektivitas Peran P3A Banda Tangah}

Efektivitas peran P3A Banda Tangah dipengaruhi beberapa faktor, berikut adalah faktor faktor yang mempengaruhi peran P3A Banda tangah dalam pengelolaan irigasi tersier diantaranya kepemimpinan P3A, waktu pertemuan P3A, fungsi tugas P3A, tingkat penguasaan materi oleh PPL, dan tingkat karya PPL. Rekapitulasi kuesioner terkait faktor faktor yang mempengaruhi peran P3A Banda tangah dalam pengelolaan irigasi tersier dapat dilihat pada lampiran 11 .
Ketua P3A Banda Tangah selaku key informan menyatakan bahwa pada operasi jaringan irigasi selalu dilakukan pengaturan air irigasi setiap 6 bulan sekali atau satu kali dalam musim tanam. Pada operasi jaringan irigasi anggota P3A tidak pernah mengeluhkan perihal kesulitan air, hal ini dikarenakan debit air yang cukup untuk lahan sawah mereka, namun apabila musim kemarau datang yang mengakibatkan debit air menurun maka dapat diatasi dengan cara bergiliran yaitu pada jam 16.00-08.00 WIB digunakan oleh P3A Banda Tangah, dan pada jam 08.00-16.00 WIB digunakan oleh P3A Bareh Solok. Pengaturan air merupakan peran utama dari Tuo Banda. Tuo Banda P3A Banda Tangah menyatakan bahwa pengaturan air irigasi penting dilakukan untuk memenuhi kebutuhan air petani agar tak adanya konflik dalam pembagian air. Kegiatan pengaturan air pada Daerah Irigasi Banda Pamujaan

Tabel 2. Pengukuran Faktor Faktor yang Mempengaruhi Efektivitas Peran P3A Banda Tangah Dalam Pengelolaan Jaringan Irigasi Tersier

\begin{tabular}{lllll}
\hline Atribut & Skor Total & Total Rata-Rata & Rata-Rata & Kategori \\
\hline Kepemimpinan P3A & 433 & 14,43 & 2,89 & Tinggi \\
Waktu Pertemuan P3A & 212 & 7,07 & 2,36 & Tinggi \\
Fungsi Tugas P3a & 79 & 2,63 & 2,63 & Tinggi \\
Tingkat Pengua saan Materi Oleh & 253 & 8,43 & 2,81 & Tinggi \\
Penyuluh & & 5,70 & 2,85 & Tinggi \\
Tingkat Karya Penyuluh & 171 & & \\
\hline
\end{tabular}

Dari data yang disajikan pada Tabel 2 dapat diketahui bahwa kelima faktor dikategorikan tinggi. Faktor dengan kategori tertinggi yaitu kepemimpinan P3A dengan rata rata 2,886, tingkat karya PPL dengan rata rata 2,85 , tingkat penguasaan materi oleh PPL dengan rata rata 2,81, fungsi tugas P3A dengan dimulai dengan dibukanya pintu air pada bangunan bendungan.

Kegiatan pembagian air menjadi tanggung jawab semua anggota P3A di setiap petak-petak tersier. Air pada DI Banda Pamujaan tergolong sangat melimpah. P3A Banda Tangah yang terdapat di DI 
Banda Pamujaan menggunakan sistem pengairan secara terus meneerus. Air tersebut mengalir dari pintu air yang berada di Batang Gawan dan mengalir dari hulu hingga hilir melalui sistem irigasi dan menggunakan sadap bagi dalam membagi airnya ke setiap petak-petak sawah tersier. Agar air masuk ke petak petak sawah masing masing, maka setiap petani akan membuka jalan di pematangnya untuk mengalirkan air ke sawah mereka.

Dalam melakukan pembuangan air, setiap petani sudah membuka jalan pada setiap petak sawah mereka. Dengan membuka aliran air pada petak tersier lalu mengalir ke saluran kwarter dari petak sawah tinggi ke petak sawah yang rendah kemudian air menuju ke saluran buang. Air dari saluran buang nantinya akan menuju ke sungai.ketika petani ingin menutup aliran air dari irigasi, maka petani tinggal menutup jalur masuk air di petak-petak sawah dengan menggunakan batu. Pembuangan air dilakukan agar padi dapat tumbuh dengan maksimal karena padi tidak butuh air pada proses pengeringan untuk panen.

Hal yang sama juga dipaparkan pada penelitian (Sari, 2017) yang menyatakan bahwa pada P3A Kola Jaya, pengaturan air irigasi tidak dilakukan setiap hari. P3A ini melakukan pengaturan air irigasi setiap akan masuk musim tanam (1 kali 6 bulan). Pengaturan air irigasi bisa dilakukan apabila kondisi air dalam kondisi baik, artinya ketersediaan air dalam jumlah yang mencukupi kebutuhan semua sawah yang ada di DI Limau Manis. Apabila terjadi musim kemarau maka pengaturan air akan dilakukan dengan cara berbeda, yaitu dengan cara pergiliran.

Pemeliharaan jaringan irigasi dimulai dari pengamanan jaringan irigasi, pemeliharaan rutin, pemeliharaan berkala sampai dengan perbaikan darurat. Menurut (Peraturan Menteri Pekerjaan Umum Dan Perumahan Rakyat (Permen PUPR) Republik Indonesia Nomor 12/PRT/M/2015 ) tentang ekploitasi dan pemeliharaan irigasi no 12/PRT/M/2015, kegiatan pengamanan jaringan irigasi adalah upaya menjaga kondisi dan fungsi jaringan irigasi serta mencegah terjadinya hal hal yang merugikan terhadap jaringan dan fasilitas jaringan, baik yang diakibatkan oleh manusia, hewan ataupun proses alami. Kegiatan pengamanan jaringan irigasi yang dilakukan oleh P3A Banda Tangah pada daerah irigasi Banda Pamujaan adalah penelusuran jaringan, mengurangi terbukanya pintu air saat musim penghujan agar kuantitas air tidak merusak jaringan irigasi serta menggomok pintu air. Kegiatan ini dilaksanakan oleh pengurus P3A, kecuali kegiatan penelusuran jaringan dilakukan oleh Tuo Banda bersama ketua kelompok tani. Biasanya, kegiatan ini dilakukan sebelum dilaksanakan sebelum masa tanam. Kegiatan ini perlu dilakukan agar bisa melihat kondisi jaringan irigasi, agar dapat dipertnimbangkan kegiatan yang bisa dilakukan demi menjaga jaringan irigasi agar tetap berada dalam kondisi yang baik. Kemudian mengatur lebar pintu air pada musim hujan dan kemarau perlu dilakukan agar ridak terjadinya air yang meluap dan merusak jarinangan irigasi.

Pemeliharaan rutin merupakan kegiatan perawatan dalam rangka mempertahankan kondisi jaringan irigasi yang dilaksanakan secara terus menerus tan pa ada bagian konstruksi yang diubah dan diganti. Berdasarkan wawancara dengan key informan P3A ini tidak selalu melakukan pemeliharaan rutin setiap harinya, karena petani tidak selalu turun kesawah setiap harinya. Adanya bangunan irigasi membuat pemeliharaan jaringan irigasi tersier menjadi lebih ringan. Kegiatan pemeliharaan rutin yang dilakuka oleh P3A Banda Tangah adalah pembersihan sampah, lumper yang menumpuk disekitar jaringan irigasi, memotong rumput dan tanamn pengganggu disepanjaang saluran irigasi.

Pemeliharaan berkala merupakan kegiatan perawatan dan perbaikan yang dilaksanakan secara berkala yang direncanakan dan dilaksanakan oleh dinas yang membidangi irigasi dan dapat bekerja sama dengan P3A/GP3A/IP3A secara swakelola berdasarkan kemampuan lembaga tersebut dan dapat dilaksanakan dengan kontraktual. Pada P3A Banda Tangah pemeliharaan berkala dilakukan oleh petani yang diawasi oleh pegurus P3A. Berdasarkan 
penuturan dari Ketua P3A Banda Tangah pemeliharaan ini tidak selalu dilakukan satu kali 6 bulan, karna melihat kondisi dari bangunan irigasi yang belum menunjukkan adanya tanda tanda kerusakan / bangunan irigasi yang jebol. Pemeliharaan berkala dilaksanakan berdasarkan kesepakatan pengurus P3A setelah melakukan penelusuran jaringan oleh Tuo Banda dan ketua kelompok tani.

Perbaikan darurat dilakukan akibat bencana alam atau kerusakan berat akibat terjadinya kejadian luar biasa dan penanggulangan segera deengan konstruksi tidak permanen agar jaringan irigasi tetap berfungsi. Kegiatan perbaikan darurat dilakukan apabila adanya jaringan irigasi yang rusak akibat bencana alam yang penanggulangannya harus dengan rekonstruksi agar jaringan irigasi tetap berfungsi sebagaimana mestinya. Bencana alam yang sering terjadi pada daerah irigasi banda pamujaan adalah banjir bandang, dan anggota P3A bergotong royong melakukan perbaikan bendungan yang rusak akibat bencana tersebut. Setelah adanya pembangunan pintu air dan pintu bendungan serta bangunan jarinagan irigasi tersier, bencana banjir bandang belum ada hingga saat ini.

Pengelolaan jaringan irigasi tersier di DI Banda Pamujaan berjalan secara optimal, dengan diperlukannya dana dalam mendukung pelaksanaan kegiatan tersebut. Berdasarkan penjelasan dari juru pengairan, P3A bersama juru pengairan telah melakukan penyusunan Rencana Anggaran Biaya (RAB) yang menggambarkan secara rinci kebutuhan untuk melaksanakan kegiatan O\&P serta rehabilitasi (kondisi baik, rusak ringan, rusak sedang ataupun rusak berat). Selanjutnya, hasil penyusunan RAB tersebut kemudian disampaikan oleh juru pengairan kepada Dinas PU untuk segera ditindak lanjuti. Dari kegiatan penyusunan anggaran tersebut, kini kondisi DI Banda Pamujaan sudah baik. Hal ini terbukti dengan kegiatan observasi yang dilakukan di lapangan. Juru pegairan juga menyatakan bahwa peran serta P3A sangat berpengaruh dalam mewujudkan pembangunan irigasi saat ini.
Berdasarkan wawancara dengan key informan P3A Banda Tangah, tidak pernah ada pelaporan terkait konflik perebutan air, hal ini dikarenakan setiap petani selalu mendapatkan air yang cukup untuk sawah mereka. Untuk tindakan pencegahan yang dilakukan oleh P3A Banda Tangah ialah dengan membangun komunikasi yang baik, suasana kekeluargaan dan rasa memiliki diantara pengurus dan petani anggota. Penanggung jawab dalam penanganan konflik ini sendiri diserahkan kepada Tuo Banda dan Ketua P3A Banda Tangah, karena untuk menangani konflik membutuhkan petinggi dari lembaga yang bersangkutan.

Hal yang sama juga terjadi pada penelitian yang dilakukan oleh (Sari, 2017) yang melakukan penelitian di P3A Kola Jaya, bahwa tidak ditemukan permasalahan. Kalaupun terjadi konflik antaran anggota P3A dilakukan penanganan konflik sesuai dengan prosedur yang telah disepakati P3A, sehingga dalam penanganannya tidak ditemukan kendala.

\section{Analisis Regresi Linear Berganda}

Untuk melihat pengaruh dari faktor faktor efektivitas peran P3A terhadap efektivitas peran P3A Banda Tangah digunakan persamaan analisis linear berganda. Dari fungsi tersebut, dapat dilihat bahwa efektivitas peran P3A Banda Tangah yang akan dianalissi terdiri dari 2 variabel, yaitu variabel dependen atau terikat $(\mathrm{X})$ dan variabel independen atau bebas (Y). Variabel dependen adalah kepemimpinan P3A (X1), waktu pertemuan P3A (X2), fungsi tugas P3A (X3), penguasaan materi oleh penyuluh (X4), tingkat kaarya penyuluh (X5) sedangkan variabel independen adalah efektivitas peran P3A Banda Tangah. Berikut persamaan regresi berganda :

$$
Y=\alpha+\beta_{1} X_{1}+\beta_{2} X_{2}+\beta_{3} X_{3}+\beta_{4} X_{4}+\beta_{5} X_{5}+e
$$

Berdasarkan hasil analisis regresi dengan menggunakan metode enter pada SPSS dapat dilihat bahwa $\mathrm{F}$ hitung > F tabel $(30,678>2,51)$ artinya variabel independen secara bersama sama berpengaruh terhadap variabel dependen. 
kepemimpinan P3A (X1), waktu pertemuan P3A (X2), fungsi tugas P3A (X3), penguasaan materi oleh penyuluh (X4), tingkat kaarya penyuluh (X5).

Berikut merupakan hasil analisis regresi antara faktor faktor efektivitas peran P3A terhadap efektivitas menjelaskan variasi variabel dependen sebesar $86 \%$. Sedangkan sisanya $14 \%$ dijelaskan oleh variabel variabel lain yang belum dimasukkan kedalam model sehingga $\mathrm{R}^{2}$ sebesar 0,86 dinyatakan bahwa model dapat menjelaskan hubungan antara variabel dependen dengan variabel independen.

Tabel 3. Hasil perhitungan analisis regresi linear berganda

\begin{tabular}{llll}
\hline Variabel & Koefisien regresi & T hitung & Signifikansi \\
\hline Konstanta & $-0,29$ & $-0,78$ & 0,44 \\
X1 & 0,45 & 4,20 & 0,00 \\
X2 & 0,41 & 4,46 & 0,00 \\
X3 & 0,10 & 1,73 & 0,10 \\
X4 & 0,14 & 2,13 & 0,04 \\
X5 & 0,03 & 0,22 & 0,83 \\
\hline
\end{tabular}

$\mathrm{F}$ hitung $=30,678, \mathrm{~F}$ tabel $=2,51$, Signifikansi uji $\mathrm{F}=0,000, \mathrm{R} 2=0,865$

Keterangan :

$\mathrm{Y}=$ Efektivitas Peran P3A Banda Tangah

$\mathrm{X} 1=$ Kepemimpinan $\mathrm{P} 3 \mathrm{~A}$

$\mathrm{X} 2$ = waktu pertemuan $\mathrm{P} 3 \mathrm{~A}$

$\mathrm{X} 3$ = fungsi tugas P3A

$\mathrm{X} 4$ = tingkat penguasaan materi oleh Penyuluh

X5 = tingkat karya Penyuluh

peran P3A Banda Tangah

Dari tabel diatas didapat persamaan regresi berganda sebagai berikut :

$$
\begin{aligned}
Y= & -0,288+0,452 X_{1}+0,407 X_{2}+0,096 X_{3} \\
& +0,141 X_{4}+0,026 X_{5}+0,200
\end{aligned}
$$

Untuk lebih jelasnya, hasil uji statistik dalam linear berganda dijelaskan sebagai berikut:

\section{Uji koefisien determinasi $\left(R^{2}\right)$}

Dari data yang diolah dengan menggunakan program SPSS didapatkan hasil nilai koefisien determinasi sebesar 0,86 (tabel ). Dari hasil regresi pengaruh variabel kepemimpinan P3A, waktu pertemuan P3A, fungsi tugas P3A, tingkat penguasaan materi oleh PPL, dan tingkat karya PPL diperoleh nilai $\mathrm{R}^{2}$ sebesar 0,86 artinya variasi variabel independen

\section{Uji F}

Penguian secara simultan digunakan untuk melihat bagaimana variabel independen secara bersama sama atau simulan mempengaruhi variabel dependen. Pengujian ini dilakukan menggunakan uji f pada tingkat sakala alfa $(\alpha) \quad 5 \%$. Hasil analisis menggunakan program SPSS menunjukkan bahwa variabel kepemimpinan P3A, waktu pertemuan P3A, fungsi tugas P3A, tingkat penguasaan materi oleh PPL, dan tingkat karya PPL (X) terhadap efektivitas peran P3A (Y), diperoleh $F$ tabel sebesar 2,51, $\alpha$ : 0,05 sedangkan $\mathrm{f}$ hitung 30,678 sehingga $\mathrm{f}$ hitung $>\mathrm{f}$ tabel $(30,678>2,51)$ dan nilai signifikan pada tabel adalah sebesar 0,000 artinya nilai signifikan $<0,05$ hal ini menunjukkan bahwa variabel independen secara simultan (bersama sama) berpengaruh signifikan terhadap varriabel dependen. 


\section{Uji T}

Dari Tabel 36 diatas dapat diketahui terdapat 3 faktor yang memiliki pengaruh yang signifikan terhadap efektivitas peran P3A Banda Tangah yaitu, kepemimpinan P3A, waktu pertemuan P3A, dan tingkat penguasaan materi oleh PPL. Sedangkan dua faktor lainnya tidak memiliki pengaruh signifikan yaitu faktor fungsi tugas P3A dan tingkat karya PPL.

1. Pengaruh Kepemimpinan terhadap Efektivitas Peran P3A Banda Tangah.

Hasil perhitungan dalam uji t menunjukkan bahwa nilai signifikansi faktor kepemimpinan (X1) memiliki signifikansi sebesar 0,000 hal ini berarti $\mathrm{H}_{0}$ ditolak karena nilai signifikan $<0,05$ dan $\mathrm{H}_{1}$ diterima, maka hubungan variabel kepemimpinan P3A (X1) terhadap efektivitas peran P3A (Y) adalah signifikan. Artinya kepemimpinan P3A memiliki pengaruh positif terhadap efektivitas peran P3A. Sehingga dapat disimpulkan kepemimpinan P3A Banda Tangah yang baik menujang efektivitas peran P3A Banda Tangah dalam pengelolaan jaringan irigasi tersier.

Menurut (Steers, 1977) kepemimpinan terjadi jika seorang individu dapat mendorong orang lain mengerjakan sesuatu atas kemauan sendiri dan bukan mengerjakan karena wajib atau karena takut akan konsekuensi dari ketidak-patuhan. Kepemimpinan sebagai tambahan pengaruh yang melebihi dan mengatasi kepatuhan mekanis pada pengarahan rutin organisasi. Hal ini dapat disimpulkan bahwa kepemimpinan P3A dapat mendorong anggotanya dalam melaksanakan tugas mereka sehingga dapat tercapainya efektivitas peran P3A Banda Tangah.

2. Pengaruh Waktu Pertemuan terhadap Efektivitas Peran P3A Banda Tangah.

Hasil perhitungan dalam uji t menunjukkan bahwa nilai signifikansi faktor waktu pertemuan (X2) memiliki signifikansi sebesar 0,000 hal ini berarti $\mathrm{H}_{0}$ ditolak karena nilai signifikan $<0,05$ dan $\mathrm{H}_{1}$ diterima, maka hubungan variabel waktu pertemuan (X2) terhadap efektivitas peran P3A (Y) adalah signifikan. Artinya waktu pertemuan P3A memiliki pengaruh positif terhadap efektivitas peran P3A. Sehingga dapat disimpulkan waktu pertemuan P3A Banda Tangah dalam intensitas cukup menujang efektivitas peran P3A Banda Tangah dalam pengelolaan jaringan irigasi tersier.

Menurut (Soedijanto, 1981) Pertemuan merupakan kesempatan untuk berkumpul bersama guna memecahkan masalah bersama, yang hendaknya mengahasilkan keputusan yang bermutu dengan memanfaatkan informasi dan perdebatan guna menyepakati rangkaian tindakan yang diperlukan. Pertemuan sangat diperlukan dalam kelompok karna dengan adanya pertemuan maka terjalinlah komunikasi dalam kelompok tersebut sehingga penyelesaian masalah dapat dilakukan dengan jalan musyawarah atau berdiskusi.

3. Pengaruh Tingkat Penguasaan Materi oleh Penyuluh terhadap Efektivitas Peran P3A Banda Tangah.

Hasil perhitungan dalam uji t menunjukkan bahwa nilai signifikansi faktor tingkat penguasaan materi oleh penyuluh (X4) memiliki signifikansi sebesar 0,044 hal ini berarti $\mathrm{H}_{0}$ ditolak karena nilai signifikan $<0,05$ dan $\mathrm{H}_{1}$ diterima, maka hubungan variabel tingkat penguasaan materi oleh penyuluh (X2) terhadap efektivitas peran P3A (Y) adalah signifikan. Artinya tingkat penguasaan materi oleh penyuluh memiliki pengaruh positif terhadap efektivitas peran P3A. Sehingga dapat disimpulkan tingkat prngusaan materi oleh penyuluh saat melakukan penyuluhan dapat menujang efektivitas peran P3A Banda Tangah dalam pengelolaan jaringan irigasi tersier.

Tingkat penguasaan materi penyuluhan merupakan kemampuan dalam menguasai materi penyuluhan kepada sasaran penyuluhan. Kemampuan penyuluh ini mempengaruhi efektivitas peran P3A karena dengan adanya penguasaan materi yang baik oleh penyuluh mampu dipahami oleh P3A secara keseluruhan. 


\section{KESIMPULAN}

Pengukuran efektivitas peran P3A Banda Tangah dalam pengelolaan jaringan irigasi tersier dalam kategori tinggi yakni dengan skor 50,83. Hal ini karena P3A Banda Tangah menjalankan perannya dengan baik, mulai dari operasi jaringan irigasi, pemeliharaan jaringan irigasi, rehabilitasi jaringan irigasi dan penanganan konflik. Namun masih terdapat penilaian buruk masyarakat seperti pada indikator Papan peringatan untuk tindakan pencegahan/preventif untuk menjaga kondisi jaringan irigasi tersier dengan skor 1,367 artinya ,petani menyatakan tidak pernah adanya papan peringatan. Selanjutnya untuk pernyataan P3A melakukan perbaikan bangunan irigasi yang tidak berfungsi dengan skor 1,367 dan P3A mangganti alat alat irigasi yang rusak dengan skor 1,423, artinya sebagian besar petani menyatakan tidak pernah melakukan perbaikan bangunan irigasi dan mengganti alat alat irigasi yang rusak.

Berdasarkan analisis menggunakan rumus interval kepemimpinan P3A, waktu pertemuan P3A, fungsi tugas $\mathrm{P} 3 \mathrm{~A}$, tingkat penguasaan materi oleh penyuluh dan tingkat penguasaan materi oleh penyuluh dalam kategori tinggi. Berdasarkan analisis regresi linear berganda, terdapat 3 faktor yang berpengaruh signifikan dengan efektivitas peran P3A Banda Tangah yaitu kepemimpinan P3A, waktu pertemuan P3A dan tingkat penguasaan materi oleh penyuluh.

\section{UCAPAN TERIMA KASIH}

Ucapan terima kasih kasih setulusnya kepada Ibu Yuerlita, S.Si., M,Si., Ph.d. dan Bapak Ferdhinal Asful, S.P., M.Si. sebagai dosen pembimbing yang telah banyak memberikan petunjuk, saran dan bimbingan selama proses penyusunan skripsi ini. Ucapan terimakasih yang sama penulis sampaikan kepada Bapak Ketua Jurusan Agribisnis dan semua pihak yang telah mambantu penulisan baik moril maupun materil dari penyusunan skripsi ini.

\section{Daftar Pustaka}

Ghozali, I. (2013). Aplika si Analisis Multivariate dengan Program SPSS. Semarang: Universitas Diponegoro.

Junita, Silviani dan Imam Buchori. (2016). Efektivitas Kelembagaan Pemerintah dalam Integrasi Pola Pengelola an Sumber Daya Air dalam Rencana Ta ta Ruang Wila yah (Studi Kasus: Provinsi Ja wa Tengah). Jurnal Wilayah Dan Lingkungan, 4, 1-12.

Peraturan Menteri Pekerjaan Umum Dan Perumahan Rakyat (Permen PUPR) Republik In donesia Nomor 12/PRT/M/2015 . (t.thn.). tentang Kriteria dan Penetapan Status Daerah Irigasi.

Ridwan. (2007). Sakal Pengukuran Variabel-Variabe Penelitian. Bandung: Alvabeta.

Saa dah et al. . (2012). Unsur-UnsurPembangunan Dalam Pengelolaan Pengairan. Jurnal Ekonomi Pembangunan, 13, 18-28.

Sari, D. N. (2017). Analisis Peran P3A Dalam Pengelolaan Jaringan Irigasi Tersier (Studi Kasus P3A Kola Jaya Daerah Irigasi (DI) Limau Manis, Kelurahan Koto Lalang, Kecamatan Lubuk Kilangan, Kota Padang). Skripsi, Universitas Andalas, Padang.

Soedijanto. (1981). Keefektifan Kelompok Tani dalam Kegiatan Penyuluhan Pertanian. Disertasi, IPB, Bogor.

Steers, R. M. (1977). Efektifitas Organisasi. Jakarta: Erlangga . 